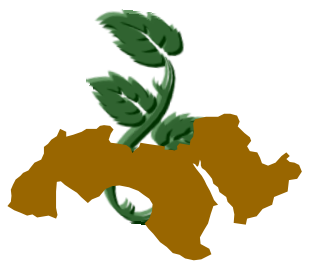

Arab Univ.

J. Agric. Sci., Ain Shams Univ., Cairo, 18(2), 307-315, 2010

\title{
IMPROVEMENT PROPERTIES OF WHEAT FLOUR USING MICROWAVE
}

\author{
Ayman, E.M. Soliman ${ }^{1}$ \\ 1- Food Technology Research Institute, Agricultural Research Center, Giza, Egypt
}

Keywords: Wheat flour, Microwave, Balady bread

\begin{abstract}
In view of balady bread in Egypt is considered as backbone in diets, accordingly, in this study wheat flour (82\%) extraction treated by microwave at 2,4 and 6 minutes, that target to modify starch wheat flour by heating. The rheological properties were studied by using farinograph and extensograph apparatus. Falling number and amylose percent were determined. Balady bread samples were sensory evaluated and staling rate was evaluated. The wheat flour, crust and crumb layers of balady bread were examined by scanning electron microscope (SEM). The results of farinograph indicated that, water absorption arrival time, dough development time and dough stability increased while dough weakening decreased in wheat flour treated by microwave compared with wheat flour untreated (control). The results of extensograph revealed that, dough extensibility, resistance to extension and dough energy increased while proportional number decreased in wheat flour treated by microwave compared with control. Falling number decreased while amylose percent increased when microwave treatment increased from 2 to 6 minutes. Sensory evaluation showed slight decrease in values of both color crust and color crumb while, values of both taste and flavor slightly increased but not significantly different, meanwhile, values of crumb distribution significantly increased in balady bread samples prepared from wheat flour treated by microwave compared with balady bread prepared from untreated wheat flour (control). Wheat flour treated by microwave led to delay staling of balady bread and imilorated freshness of balady bread. The examination by scanning electron microscope (SEM) showed that average size of starch granules increased from $26.10 \mu \mathrm{m}$ in untreated wheat flour (control) to $29.37 \mu \mathrm{m}$ in treated wheat flour by microwave at 6 minutes.
\end{abstract}

\section{INTRODUCTION}

Wheat is the most widely cultivated cereal in the world and its products are very important in human nutrition. In many parts of the world where wheat cannot be grown it is imported and is becoming an increasingly important part of the diet, especially for the urban population. However, importation of wheat, like that of all products, must be offset by adequate exports to prevent a drain on a country's foreign exchange. Bread, usually made from wheat flour, is a popular convenience food. When purchased, it saves time and fuel for poor families (Michael 1997).

The problem of wheat quality seems to be more complicated in Egypt because wheat or enduse products such as wheat flour are imported from several countries. Significant differentiation in the genetic and environmental origin of imported wheat grains (flour) as well as improper storage conditions affect the technological quality of flour. Considering these reasons, many studies have intentionally indicated the possibility of supplementation of wheat flour components in order to increase the quality of bakery products (Ragab et al 2005).

Microwave energy has been used in food applications mainly for its heating properties. It seems natural, therefore, to adapt microwave radiation to pasteurizing or even sterilizing foods at lower temperatures or in shorter times than conventional methods require. Several researchers have attempted to ascertain if such radiation has a nonthermal effect on microorganisms. Regardless of the mode of action, microwave radiation has been reported to be feasible for achieving longer shelf life of several food products. Theoretically, if the technique were adapted to commercial use, considerable energy saving could result (Joanna et al 2003).

Microwave energy is generated by the interaction of microwaves with charged and polar mole- 
cules of food components. Heating by microwaves offer a lot of advantages such as less start-up time, shorter time of treatment, faster heating, energy saving, energy costs less, microwave equipment requires less space, selective heating, high nutritional quality final product and destruction of microorganisms by microwave (Sumnu, 2001).

The target of this research was studying the effect of microwave treatment on rheological properties, falling number and amylose content of wheat flour $(82 \%)$ extraction, determination of staling rate and sensory evaluation of balady bread and examination of wheat flour, crust and crumb layers of balady bread by scanning electron microscope (SEM).

\section{MATERIALS AND METHODS}

\section{Materials}

Wheat flour (82\% extraction) was obtained in 2009 from Middle and West Delta Mills Company, Shebin El-Kom City, Minufiya Governorate, Egypt.

\section{Methods}

\section{Microwave treatment}

Wheat flour (82\% extraction) was treated by Samsung microwave Made in Thailand, Model ME61245T microwave oven 1000 Watt output power and $2450 \mathrm{MHz}$ microwave frequency. Microwave treatment was carried out for 2,4 and 6 minutes.

\section{Determination of gross chemical analysis}

Moisture, protein, fat, fiber, and ash content were determined according to the methods of AOAC (2005).

\section{Rheological properties}

The rheological properties of the different dough were carried out using farinograph and extensograph apparatus according to the methods described in AACC (2002).

\section{Falling number}

The falling number was determined according to AACC (2002).

\section{Determination of amylose}

Amylose content was determined as described by William et al (1970). The absorbance was measured at $625 \mathrm{~nm}$ using spectrophotometer shimadzu UN-1201 (made in Germany). Amylose content was calculated by standard curve using pure amylose.

\section{Preparation of balady bread}

One $\mathrm{kg}$ of wheat flour (82\%) was mixed with water (that was previously identified on the basis farinograph test), $1.5 \%$ sodium chloride, $1.5 \%$ compressed yeast. The ingredients were kneaded for $20 \mathrm{~min}$. in mixer laboratory mechanical. The dough was fermented for one hr. at $30^{\circ} \mathrm{C}$ under $85 \%$ relative humidity $(\mathrm{RH})$. Dough was divided into $160 \mathrm{gm}$ pieces. Pieces were moulded on a wooden board previously sprinkled with fine layer of bran and left for $15 \mathrm{~min}$. at $30^{\circ} \mathrm{C}$ and $85 \%(\mathrm{RH})$. The pieces were flattend to about $20 \mathrm{~cm}$ diameter and $0.5 \mathrm{~cm}$ thickness then proofed at $30^{\circ} \mathrm{C}$ and $85 \%(\mathrm{RH})$ for $30 \mathrm{~min}$. then baked at $450-500^{\circ} \mathrm{C}$ for 1-2 min. in electric oven. Bread loaves were allowed to cool on rack for $30 \mathrm{~min}$. before organolyptic evaluation, then packed in polyethylene bags (Mohamed et al 1996).

\section{Sensory evaluation}

The balady bread loaves were sensory evaluated for crust color, crumb color, crumb, distribution, taste and flavor according to method of Mohamed et al (1996).

\section{Determination of staling rate}

After baking the bread was cooled at room temperature. Bread freshness was determined at zero time, after 24 and $48 \%$ hr. of storage by Alkaline Water Retention Capacity (AWRC) according to the method of Kitterman and Rubenthaler (1971).

\section{Scanning electron microscope (SEM)}

Samples were examined according to the method of Lorenz (1979) using scanning electron microscope (Model JEOL, JEM-1230, Tokyo, Japan). 


\section{Statistical Analysis}

The obtained results were analyzed using Statistical Analysis System SAS (2001).

\section{RESULTS AND DISCUSSION}

\section{Chemical composition}

An adequate knowledge of the chemical composition of food is vital to the health, well-being and safety of the consumer.

With respect to chemical composition of wheat flour (82\% extraction), the results in Table (1) demonstrated that wheat flour contained $11.82 \%$ moisture, $11.55 \%$ protein, $1.80 \%$ fat, $1.74 \%$ fiber, $1.31 \%$ ash and $83.60 \%$ carbohydrates. These results are in accordance with those obtained by Mohamed et al (2009). They found that wheat flour $(82 \%)$ extraction contained $11.45 \%$ moisture, $11.51 \%$ protein, $1.72 \%$ fat, $1.89 \%$ fiber, $1.50 \%$ ash and $83.38 \%$ carbohydrates. The slight difference in two results may be ascribed to either wheat variety, growth environment, fertilizer application or time harvesting.

\section{Rheological properties}

The rheological measurements employed at the present time is capable of fully predicting the end performance of a flour and flour product. These measurements serve as indices when property interpreted, enhance the probability of satisfactory end-performance. It is apparent that the ultimate criteria of quality in flour are its conformance to physical requirement plus certain standards as established by a performance test.

Concerning farinograph parameters, the data in Table (2) indicated that microwave treatment for wheat flour at 2, 4 and 6 minutes caused increasing in water absorption whereas it found to be $59.3,61.1$ and $62.0 \%$ respectively compared with wheat flour untreated by microwave (control) (57.6\%). This increase could be related to the treatment of wheat flour by microwave led to improve the hygroscopic properties of starch, therefore starch becomes more able to absorb water and increase in water binding capacity as mentioned by Lorenz (1981). Form the same table it could be observed that, microwave treatment for wheat flour at 2, 4 and 6 minutes slightly augmented arrival time which recorded 1.5, 1.5 and $1.5 \mathrm{~min}$ respectively compared with control $(1 \mathrm{~min})$. This augmentation in arrival time may be due to the slow hydration and extended time required to develop optimum gluten net work in dough as reported by Lorenz (1981). It could be also noticed from same table that both dough development time and dough stability took the same trend whereas increased in wheat flour treated by microwave at 2, 4 and 6 minutes which recorded 2, 2 and $2.5 \mathrm{~min}$ respectively for dough development time compared with control which recorded $1.5 \mathrm{~min}$, while recorded $3,3.5$ and 4 min for dough stability respectively compared with control $(2.5 \mathrm{~min})$. At the same time, dough weakening improved in wheat flour treated by microwave at 2, 4 and 6 minutes whereas it found to be 70,70 and $60 \mathrm{BU}$ respectively compared with control (80 BU). These results are in agreement with Daftary et al (1970), who stated that strong flour usually require longer mixing times and stability with lower weakening property.

With regard to extensograph parameters, the present results in Table (3) declared that dough extensibility, resistance to extension and dough energy increased while proportional number decreased when wheat flour treated by microwave at 2, 4 and 6 minutes compared with wheat flour untreated (control). Whereas it for dough extensibility found to be 145, 155 and $160 \mathrm{~mm}$ compared with control $(140 \mathrm{~mm})$, for resistance to extension found to be 365,370 and $380 \mathrm{BU}$ respectively compared with control (355 mm), for proportional number found to be $2.51,2.38$ and 2.37 respectively compared with control (2.53) and for dough energy found to be $80.1,83.4$ and $85.2 \mathrm{~cm}^{2}$ respectively compared with control $\left(78.4 \mathrm{~cm}^{2}\right)$. In the same context Betty et al (2001) reported that the increasing of dough energy lead to increase in loaves volume. The treatment wheat flour by microwave lead to inhibition of protease enzyme, thus increase aggregation of particles proteins flour during dough preparation and increase ability gluten on preservation of carbon dioxide.

\section{Falling number}

Respecting falling number, the results in Table (4) revealed that falling number decreased when time microwave treatment of wheat flour increased at 2, 4 and 6 minutes which recorded 320,317 and 311 second respectively compared with wheat flour untreated (control) (325 second), vice-versa, amylose content, increased when time microwave treatment of wheat flour increased at 2, 4 and 6 
Table 1. Chemical composition (\%) of wheat flour (on dry weight basis)

\begin{tabular}{|l|c|c|c|c|c|c|}
\hline Samples & Moisture & Protein & Fat & Fiber & Ash & Carbohydrates $^{* *}$ \\
\hline Wheat flour (82\%) & 11.82 & 11.55 & 1.80 & 1.74 & 1.31 & 83.60 \\
\hline
\end{tabular}

* Each value is mean of duplicate determination.

** Calculated by difference.

Table 2. Farinograph parameters of wheat flour (82\%) treated by microwave

\begin{tabular}{|l|c|c|c|c|c|}
\hline \multicolumn{1}{|c|}{ Treatments } & $\begin{array}{c}\text { Water } \\
\text { absorption } \\
(\%)\end{array}$ & $\begin{array}{c}\text { Arrival } \\
\text { time } \\
(\mathbf{m i n})\end{array}$ & $\begin{array}{c}\text { Dough } \\
\text { development } \\
\text { time (min) }\end{array}$ & $\begin{array}{c}\text { Dough } \\
\text { stability } \\
(\mathbf{m i n})\end{array}$ & $\begin{array}{c}\text { Dough } \\
\text { weakening } \\
\text { (BU) }\end{array}$ \\
\hline Wheat flour untreated by microwave (control) & 57.6 & 1 & 1.5 & 2.5 & 80 \\
Wheat flour treated by microwave at 2 minutes & 59.3 & 1.5 & 2 & 3.0 & 70 \\
Wheat flour treated by microwave at 4 minutes & 61.1 & 1.5 & 2 & 3.5 & 70 \\
Wheat flour treated by microwave at 6 minutes & 62.0 & 1.5 & 2.5 & 4.0 & 60 \\
\hline
\end{tabular}

Table 3. Extensograph parameters of wheat flour (82\%) treated by microwave

\begin{tabular}{|l|c|c|c|c|}
\hline \multicolumn{1}{|c|}{ Treatments } & $\begin{array}{c}\text { Dough } \\
\text { extensibility } \\
\mathbf{( E , ~} \mathbf{~ m m})\end{array}$ & $\begin{array}{c}\text { Resistance } \\
\text { to extension } \\
\mathbf{( R , ~ B U )}\end{array}$ & $\begin{array}{c}\text { Proportional } \\
\text { number } \\
\mathbf{( R / E )}\end{array}$ & $\begin{array}{c}\text { Dough } \\
\text { energy } \\
\left.\mathbf{( c m}^{2}\right)\end{array}$ \\
\hline Wheat flour untreated by microwave (control) & 140 & 355 & 2.53 & 78.4 \\
Wheat flour treated by microwave at 2 minutes & 145 & 365 & 2.51 & 80.1 \\
Wheat flour treated by microwave at 4 minutes & 155 & 370 & 2.38 & 83.4 \\
Wheat flour treated by microwave at 6 minutes & 160 & 380 & 2.37 & 85.2 \\
\hline
\end{tabular}

Table 4. Falling number and amylose content of wheat flour $(82 \%)$ treated by microwave

\begin{tabular}{|l|c|c|}
\hline Treatments & Falling number (sec) & Amylose (\%) \\
\hline Wheat flour untreated by microwave (control) & 325 & 25.36 \\
Wheat flour treated by microwave at 2 minutes & 320 & 25.81 \\
Wheat flour treated by microwave at 4 minutes & 317 & 26.50 \\
Wheat flour treated by microwave at 6 minutes & 311 & 26.98 \\
\hline
\end{tabular}


(control) (25.36). Baszczak et al (2004) reported that it is well known that there is a reversible relationship between falling number and alphaamylase activity. Falling number is an practical indication used in the production of bakery products. It is considered as an indicator for amylase activity (the greater the amylolytic activity, the shorter is the time required) of wheat flour dough and the effect of addition other cereals. The standard falling number is between 250-350 sec. Increase activity of alpha-amylase lead to decrease of maximum viscosity and increase of both gelatinization starch and amylose units, hence, increase of dough on carbon dioxide production. On the other hand, the amylose content in wheat starch was ranged from 24.8 to $34.2 \%$ as reported by Sasaki and Matsuki (1998).

\section{Sensory evaluation}

Sensory evaluation is considered as an important indicator of potential consumer preferences. In spite of its short comings it will remain one of the most reliable quality assessment technique for food and food products in general and for bread and bakery products in particular.

In relation to sensory evaluation of balady bread samples, the data in Table (5) evinced that values of both crumb color and crust color slightly decreased while, values of both taste and flavor slightly increased but did not significantly different in balady bread samples prepared from wheat flour treated by microwave compared with balady bread prepared from wheat flour untreated by microwave (control). Meanwhile, values of crumb distribution significantly increased in balady bread samples prepared from wheat flour treated by microwave compared with balady bread prepared from wheat flour untreated by microwave (control). In the same context Sumnu (2001) reported that baking is a complex process that brings about a series of physical, chemical and biochemical changes in food such as gelatinization of starch, denaturation of protein, liberation of carbon dioxide from leavening agents, volume expansion, evaporation of water, crust formation and browning reactions. It can be described as a simultaneous heat and mass transfer within the product and with the environment inside the oven.

\section{Staling of balady bread}

Regarding staling of balady bread, the data in Table (6) showed that alkaline water retention capacity (AWRC) were decreased as storage period of balady bread increased in balady bread samples prepared from wheat flour treated by microwave compared with balady bread prepared from wheat flour untreated by microwave (control). The results indicated that microwave treatment caused improving in freshness and delay or retarded staling of balady bread. This increasing in freshness may be attributed do to increasing in solubility of starch. The mechanism of the antistaling function of alphaamylase is thought to be that starch chains that connect different crystalline domains are broken. The crystalline network will then be of a smaller dimension (Baszczak et al 2004).

\section{Scanning electron microscope (SEM)}

Examination of the microstructure of wheat flour and bread has been helpful in determining the changes that occur in physical structure during the various stages of bread preparation.

In respect of examination by scanning electron microscope (SEM), from Table (7) and Fig (a \& b) deduced that average size of starch granules increased from $26.10 \mu \mathrm{m}$ in wheat flour untreated by microwave (control) to $29.37 \mu \mathrm{m}$ in wheat flour treated by microwave at 6 minutes. Also, Fig. (a \& b) delineated that the shape of starch granules is oval. The microstructure of the crust and crumb layers of control bread (Fig. c \& e) (prepared from wheat flour untreated by microwave) seemed to be less visible, cell matrix unequal and increasing in boring or piercing. The microstructure of the crust and crumb layers of balady bread (Fig. d \& f) (prepared from wheat flour treated by microwave at 6 minutes) found to be the structural nearly uniform distribution when compared with control.

It can be concluded based on the findings of the present study that microwave treatment could be recommended for wheat flour because microwave treatment gave the satisfactory results and can be used safely for industrial application in order to decrease the waste of balady bread loaves, then decrease importe quantities wheat to save hard currency. 
Table 5. Sensory evaluation of balady bread ${ }^{*}$

\begin{tabular}{|l|c|c|c|c|c|}
\hline \multicolumn{1}{|c|}{ Samples } & $\begin{array}{c}\text { Crumb color } \\
\mathbf{( 2 0 )}\end{array}$ & $\begin{array}{c}\text { Crust color } \\
\mathbf{( 2 0 )}\end{array}$ & $\begin{array}{c}\text { Crumb } \\
\text { Distribution } \\
\mathbf{( 2 0 )}\end{array}$ & $\begin{array}{c}\text { Taste } \\
\mathbf{( 2 0 )}\end{array}$ & $\begin{array}{c}\text { Flavor } \\
\mathbf{( 2 0 )}\end{array}$ \\
\hline Bread (control) & $18.93 \pm 0.68 \mathrm{a}$ & $18.73 \pm 0.89 \mathrm{a}$ & $17.46 \pm 0.51 \mathrm{~b}$ & $18.10 \pm 0.75 \mathrm{a}$ & $18.17 \pm 0.42 \mathrm{a}$ \\
Bread (1) & $18.86 \pm 0.71 \mathrm{a}$ & $18.69 \pm 0.75 \mathrm{a}$ & $17.54 \pm 0.65 \mathrm{~b}$ & $18.22 \pm 0.91 \mathrm{a}$ & $18.35 \pm 0.58 \mathrm{a}$ \\
Bread (2) & $18.81 \pm 0.90 \mathrm{a}$ & $18.66 \pm 0.92 \mathrm{a}$ & $17.63 \pm 0.49 \mathrm{ab}$ & $18.39 \pm 0.87 \mathrm{a}$ & $18.43 \pm 0.62 \mathrm{a}$ \\
Bread (3) & $18.77 \pm 0.65 \mathrm{a}$ & $18.60 \pm 0.59 \mathrm{a}$ & $18.61 \pm 0.58 \mathrm{a}$ & $18.55 \pm 0.65 \mathrm{a}$ & $18.61 \pm 0.80 \mathrm{a}$ \\
\hline L.S.D. (0.05) & 0.27 & 0.31 & 0.40 & 0.81 & 0.77 \\
\hline
\end{tabular}

* Values are mean \pm standard error

* Values in the same column with different superscript letters $(a, b$...) are significantly difference

${ }^{* *}$ Bread 1, 2 \& 3 prepared from wheat flour treated by microwave at 2, 4 and 6 minutes respectively

Table 6. Alkaline water retention capacity (AWRC) (\%) of stored balady bread

\begin{tabular}{|l|c|c|c|c|c|}
\hline Samples & Zero time (fresh) & After 24 hr. & R.D (\%) & After $\mathbf{4 8 ~ h r . ~}$ & R.D (\%) \\
\hline Bread (control) & 351 & 343 & 2.27 & 333 & 2.91 \\
Bread (1)** & 356 & 350 & 1.68 & 342 & 2.28 \\
Bread (2) & 364 & 359 & 1.37 & 353 & 1.67 \\
Bread (3) & 369 & 365 & 1.08 & 360 & 1.36 \\
\hline
\end{tabular}

${ }^{*}$ R.D $=$ Rate of decrease.

** Bread 1, 2 \& 3 prepared from wheat flour treated by microwave at 2, 4 and 6 minutes respectively.

Table 7. Size of wheat starch granules as affected by microwave treatment measured by scanning electron microscope (SEM)

\begin{tabular}{|l|c|c|c|}
\hline \multicolumn{1}{|c|}{ Treatments } & Size range $(\mu \mathrm{m})$ & Average $(\mu \mathrm{m})$ & Changes (\%) \\
\hline Wheat flour untreated by microwave (control) & $25-27.33$ & 26.10 & - \\
Wheat flour treated by microwave at 6 minutes & $28.15-30.63$ & 29.37 & 0.12 \\
\hline
\end{tabular}




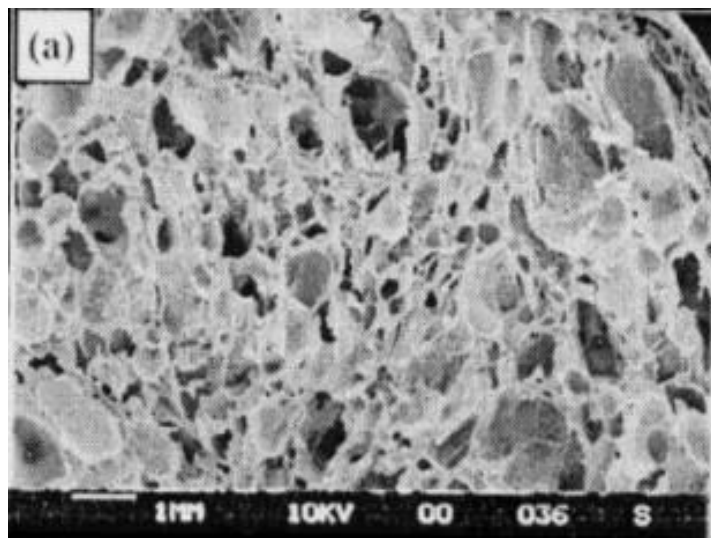

Fig. a. Scanning electron micrograph of wheat flour untreated by microwave (control).

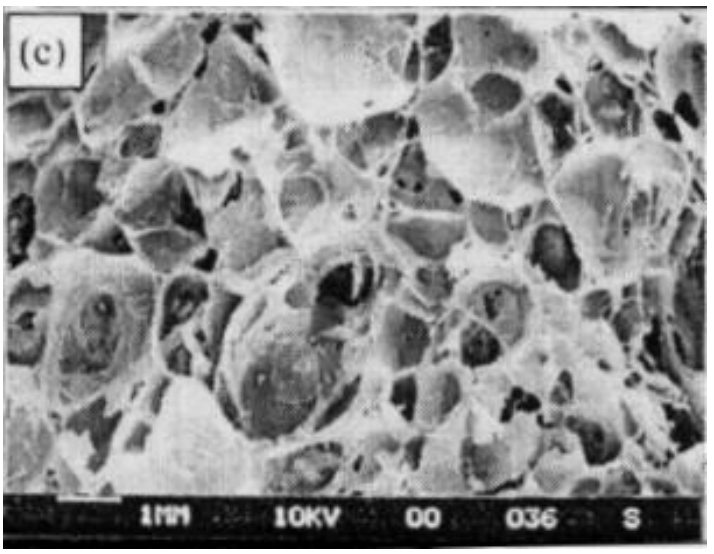

Fig. c. Scanning electron micrograph of crust bread prepared from wheat flour untreated by microwave (control).

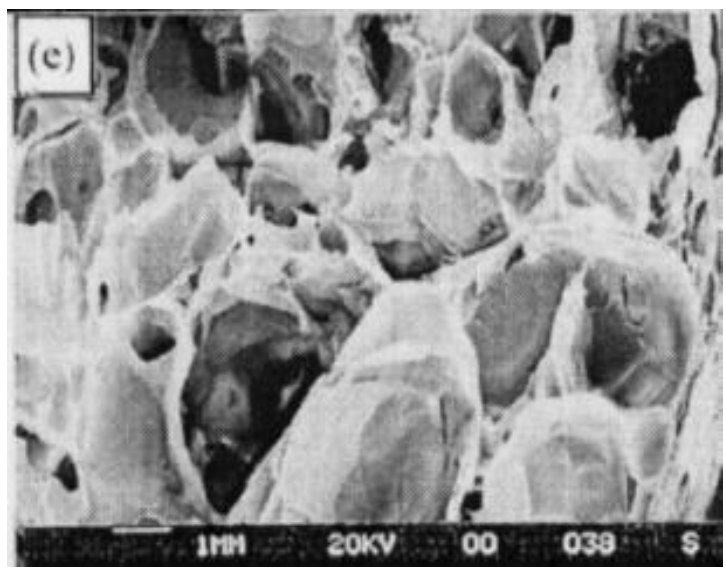

Fig. e. Scanning electron micrograph of crumb bread prepared from wheat flour untreated by microwave (control).

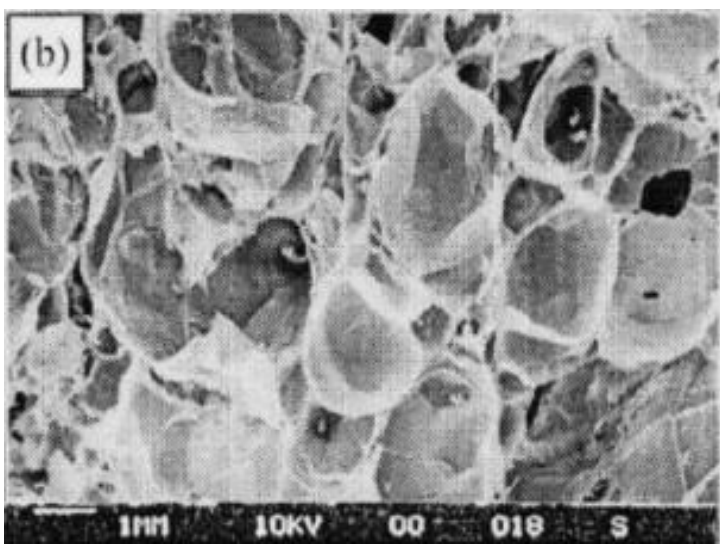

Fig. b. Scanning electron micrograph of wheat flour treated by microwave at 6 minutes.

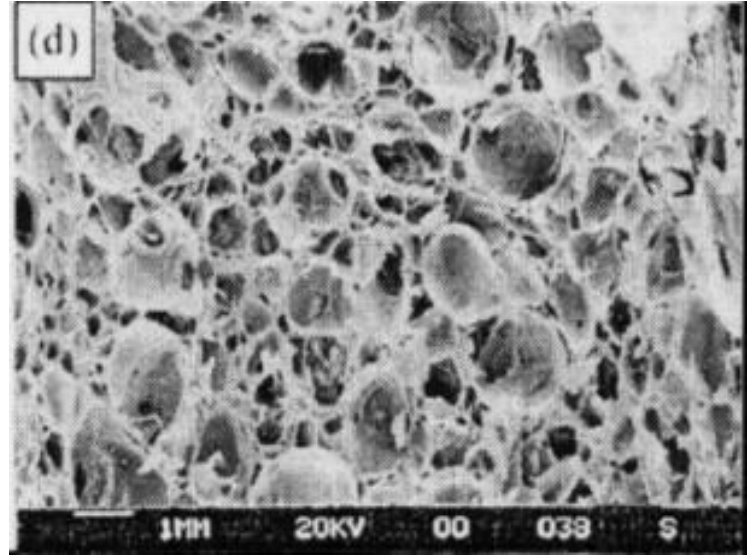

Fig. d. Scanning electron micrograph of crust bread prepared from wheat flour treated by microwave at 6 minutes.

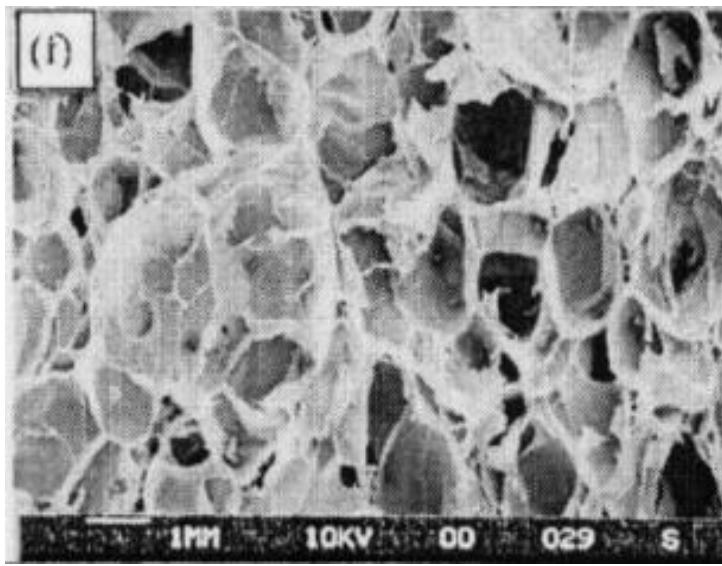

Fig. f. Scanning electron micrograph of crumb bread prepared from wheat flour treated by microwave at 6 minutes. 


\section{REFERENCES}

AACC (2002). Approved Methods of American Association of Cereal Chemists. Inc., St. Paul, Minnesota, USA.

AOAC (2005). Official Methods of Analysis. $18^{\text {th }}$ Ed. Association of Official Analytical Chemists. Arlington, Virginia, USA.

Baszczak, W.; J. Sadewska; C. Rosell and J. Fornal (2004). Structural changes in the wheat dough and bread with the addition of alpha-amylases. Eur. Food res. Technol., 219: 348-354.

Betty, A.; C. Osuvaldo and R. Bruce (2001). Improvement of sorghum-wheat composite dough rheological properties and breadmaking quality through zein addition. Cereal Chem., 78(1): 31-35.

Daftary, R.V.; Y. Pomeranz and P.B. Sauer (1970). Changes in wheat flour damaged by mold during storage. Effect on lipid, liprotein and protein. J. Agric. Food Chem., 18(4): 613-616.

Joanna, L.; L. Agata; S. Janusz; L. Jolanta and Z. Henryk (2003). The effect of microwave treatment on the immunoreactivity of gliadin and wheat flour. Eur. Food Res. Technol., 217: 387-391.

Kitterman, J.S. and G.L. Rubenthaler (1971). Assessing the quality of early generation wheat selection with the micro AWRC test. Cereal Sci. Today, 16(8): 313-318.
Lorenz, K. (1979). The starch of the faba bean (Vicia faba) comparison with wheat and corn starch. Starch, 31: 181-184.

Lorenz, K. (1981). The starch of wild rice (Zizamia aquatica). Starch, 33: 73-76.

Michael, C.L. (1997). Human Nutrition in the Developing World p. 259. Published by Food and Agriculture Organization of the United $\mathrm{Na}$ tions, Rome.

Mohamed, M.R.; A.A. Atia; A. Hussein and N.H. Assem (1996). Effect of wheat flour and yeast on balady bread characteristics. Egypt $\mathbf{J}$. Food Sci., 24(1): 81-92.

Mohamed, A.E.; N.M. Abd-Elmotaleb and H.A. Baumy (2009). Bioavailability of calcium from different sources for balady bread fortification. Egypt. J. Food Sci., 37(1): 26-38.

Ragab, G.; W. Baszczak; J. Fornal and A. Ramy (2005). Effect of surfactants on the rheological behaviour of biscuit dough quality and microstructure. Egypt J. Food Sci., 33(1): 1-13.

Sasaki, T. and J. Matsuki (1998). Effect of wheat starch structure on swelling power. Cereal Chem., 75(4): 525-529.

SAS (2001). Statistical Analysis System. SAS User's Guide: Statistics (Version 6.0). SAS Inst. Inc. Cary. NC. USA.

Sumnu, G. (2001). A review on microwave baking of foods. International J. of Food Science and Technol., 36: 117-127.

William, P.C.; F.D. Kuzina and I. Hlynka (1970). A rapid colormetric procedure for estimating the amylose content of starches and flours. Cereal Chem., 47: 411-420. 